\title{
LA DOCTRINA DE LA CAUSA Y SU EFICACIA PRÁCTICA
}

\section{THE DOCTRINE OF CAUSE AND ITS PRACTICAL EFECTIVENESS}

\author{
Jorge Baraona GonzÁlez*
}

\begin{abstract}
RESUMEN: Con fecha nueve de mayo de 2011, el prestigioso profesor de Filosofía del Derecho y de Derecho Civil en la Facultad de Derecho de la P. Universidad Católica de Chile, don José Joaquín Ugarte Godoy, actuando como árbitro, dictó una sentencia que tiene importancia doctrinal.
\end{abstract}

Palabras clave: Teoría de la causa, justicia arbitral, contrato de agenciamiento hotelero.

ABSTRACT: On May 9th, 2011, the prestigious profesor of Philosophy of Law and Civil Law at The P. Universidad Católica de Chile, Mr. José Joaquín Ugarte Godoy, acting as arbitrator, delivered a judgment with doctrinal importance.

Key words: Theory of causation, arbitration, hotel agency contract.

La sentencia se refiere a un caso de los denominados contratos de agenciamiento hotelero, en la cual el actor demandó a una sociedad por el supuesto incumplimiento de un contrato por el cual el demandado lo hacía partícipe de un sistema denominado "Multivacaciones", vinculado a un hotel de Pucón. El contrato suponía que, por una cantidad de once millones y fracción de pesos, equivalentes a 620 Unidades de Fomento, pagaderos en un $25 \%$ por ciento al contado y el resto en 48 cuotas mensuales, con un interés de un $17,7 \%$, más seguro de desgravamen, el interesado adquiría una serie de beneficios. Las contraprestaciones que se le ofrecían eran: a) adquirir la calidad de miembro por veinticinco años en el sistema "multidestinos" del hotel de Pucón; b) adquirir la calidad de miembro por 25 años de un sistema internacional de intercambios llamado "RCI" que le permitía el acceso a cientos de hoteles de todo el mundo. Los beneficios se extendían hasta 6 personas del grupo familiar. Cuando el cliente firmó el contrato, al mismo tiempo exigió la suscripción de un anexo por el cual la agencia precisara ciertos aspectos del beneficio que entregaría, documento que nunca se firmó. El actor decidió demandar a la agencia, pidiendo la resolución del contrato y, entre otros aspectos, reclamó que el contrato incluía una cláusula que establecía que el usuario debía pagar al establecimiento de vacaciones que elija una "cuota de servicio" por su alojamiento, cuyo valor se determinaba en el reglamento de cada hotel o complejo turístico. El actor demandó, pues el contrato le aseguraba que el costo semanal por el hotel sería de quinientos dólares semanales y con esa cláusula el costo del alojamiento sería "ciento por ciento variable y desconocido". Explicó el actor que, para remediar esa situación, había pedido a la agencia un anexo contractual, que esta se comprometió a firmar y no lo hizo, configurándose así un incumplimiento del contracto. Pidió, además de la resolución del contrato, la restitución de lo pagado como parte de contado y el daño

*Profesor de Derecho Civil y Decano de la Facultad de Derecho, Universidad de los Andes. 
emergente por una cantidad que superaba los \$4.000.000. En el juicio la demandada no contestó a la demanda.

El señor José Joaquín Ugarte, actuando como se ha dicho en calidad de árbitro, antes de analizar las pretensiones de la demandante, se detuvo en un hecho que lo llevó a recurrir a la norma contenida en el artículo 1683 del Código Civil, para declarar nulo absolutamente el contrato, por las consideraciones que en la misma sentencia se consignan y que a continuación transcribo:

"7 Que la cláusula séptima del contrato en examen, se dice que los precios a pagar por los hoteles en que quiera alojarse el actor serán los que determine el reglamento del respectivo hotel.

$8^{\circ}$ ) Que mediante el contrato de marras, la demandada se obliga a tener para el actor en los períodos de vacaciones, hospedaje en hoteles de Chile y en el extranjero para él y su familia -con un máximo de seis personas- a precios que se supone han de ser inferiores a los corrientes, suposición que se funda en la naturaleza de este tipo de contratos, en que se exige un pago anticipado del hospedaje futuro, y que miran a asegurar un mínimo de clientes a los hoteles, especialmente en determinados períodos, a cambio de ofrecer a estos condiciones económicamente ventajosas; obligándose a su vez el actor para con la demandada, a pagarle una comisión por el indicado servicio, sin perjuicio del pago que ha de hacer por el hospedaje en los hoteles que utilice de hecho en cada oportunidad, pago que hará con cargo al precio que entrega al efecto a la demandada, que es intermediaria -según se lee en la cláusula octava- mediante cupones que esta le proporciona para darlos en pago en el respectivo hotel.

$9^{\circ}$ Que el contrato de agenciamiento hotelero contiene así la obligación de tener un hospedaje en épocas de vacaciones, que sea económicamente ventajoso para el interesado en tomarlas, obligación que ha de cumplir la empresa que actúa como agente; y contiene también una verdadera promesa de hecho ajeno, que han de cumplir los establecimiento hoteleros respectivos, llegado el caso, de proporcionar el alojamiento a un precio inferior al usual, y que por tanto resulte ventajoso, mediante el respectivo contrato de hospedaje, que el interesado celebrará directamente con el hotel que elija cuando use el programa a que el agente hotelero lo ha incorporado mediante una comisión que él percibe.

$10^{\circ}$ ) Que la causa que ha de tener todo acto o declaración de voluntad, según el art. 1445 de nuestro Código Civil, y sin la cual no puede haber obligación, al tenor del artículo 1467 del mismo cuerpo de leyes, es "el motivo que induce al acto o contrato", como reza la definición que hace este último precepto, y es, por tanto, una causa final, que ha de ser entonces, preconocida por el agente y luego aceptada por su voluntad, para ser en definitiva conseguida, siendo la causa final, como ha dicho la Corte de Temuco, en un notable fallo redactado por don Jorge Mera, autor de un libro fundamental en Chile sobre la doctrina de la causa, la primera en el orden de la intención y la última en el orden de la consecución (Revista de Derecho y Jurisprudencia, t. 78, sección $2^{\circ}$, pág 1).

$11^{\circ}$ ) Que la causa ha de ser real, como lo dispone el artículo 1467 del Código Civil, de modo que sirva de razón de ser del acto jurídico y a las obligaciones que de él emanen; y que no pueden ser causa real que sirva de razón de ser al acto jurídico y a la obligación de que se trate, la constituida en un contrato patrimonial por una ventaja económica que 
puede revestir cualquier magnitud, incluso una insignificante, como ocurre en la especie, en que no se estipula límite alguno, máximo ni mínimo, para los precios que ha de pagar el actor a los hoteles en que se aloje, resultando inconcebible que pueda existir a cargo suyo una obligación de pagar anticipadamente -en parte importante- el precio de hospedajes futuros, para obtener una ventaja imposible de conocer y valorar, sin que por otra parte se trate de un contrato aleatorio, pues su finalidad es precisa y únicamente que un padre de familia se asegure unas vacaciones.

$12^{\circ}$ Que, en consecuencia, el contrato en cuestión es absolutamente nulo, por falta de causa, ocurriendo, además, que la indeterminación de la ventaja que podría traerle al actor, y que acarrea la falta de causa, aparece de manifiesto en el contrato, con la remisión que en él se contiene a los reglamentos de los hoteles en que el demandante quiera hospedarse, para determinar el precio que ha de pagarse es por el alojamiento.

$13^{\circ}$ Que apareciendo la nulidad absoluta señalada, de manifiesto en el acto o contrato, este sentenciador deberá declarar de oficio, con arreglo al artículo 1683 del Código Civil”.

La lectura de estos magníficos considerandos, escritos por lo demás con una extraordinaria pluma, motiva varios comentarios.

En primer lugar, el árbitro desatiende la petición principal del actor, para analizar, con mayor profundidad, la validez del contrato. En criterio del juez árbitro, dado los hechos según quedaron acreditados, la cuestión planteada es mucho más que de incumplimiento, un tema de validez contractual.

La indagación por la presunta invalidez del contrato lleva al árbitro a cuestionarse la plausibilidad de considerar suficientemente causado el contrato mismo y las obligaciones que de él derivan y, a propósito de la causa contractual, expone consideraciones profundas. Sabemos que la cuestión de la causa de los actos jurídicos (también de las obligaciones) ha sido, y sigue siendo, un tema polémico en la dogmática del Derecho civil, tanto nacional como comparada, y que la disputa histórica que se dio en el Derecho francés llega hasta nuestros días. De hecho, el mismo artículo 1467 del Código Civil ha coadyuvado a incrementar la confusión.

El profesor Ugarte claramente se aproxima a la causa del contrato, incluyendo a la obligación consecuente, entendida como causa final, y advierte que la idea de motivo que refiere el artículo 1467 del Código Civil ha de ser preconocida, es decir, se debe tratar de una realidad extramental y operativa, en cuando sirve como elemento para mover a la acción y en cuando constituye una finalidad que debe ser conseguida o alcanzada. Es decir, conforme con esta doctrina, la causa del contrato no se afinca en la pura motivación intrínseca del sujeto, sino que está apoyada a una realidad, social si se quiere, que se busca modificar, es conocida por el sujeto y aparece como un elemento que le motiva en su actuación jurídica. De esta manera rompe el árbitro en su fallo con la rigidez de la teoría clásica de la causa, asociada a las causa de las obligaciones y que apunta únicamente a aspectos estructurales del contrato, desentendiéndose de la motivación que ha tenido el sujeto, excepto el caso de los actos a título gratuito. Conecta la teoría de la causa con la necesidad de que el contrato responda a un verdadero acto humano, es decir que exista en el sujeto actuante, entre otros elementos, un conocimiento del fin buscado y voluntad de alcanzarlo. 
En el considerando que sigue, el árbitro hace otra afirmación profunda y sólida, cuando afirma que la causa ha de ser real y debe servir "de razón al acto jurídico y a las obligaciones que de él emanen, y que no puede ser causa real que sirva de razón de ser al acto y a la obligación de que se trate, la constituida en un contrato patrimonial por una ventaja económica que puede revestir cualquier magnitud, incluso una insignificante, como ocurre en la especie...”. De aquí parece reafirmarse la doctrina clásica, cuando establece que entre las prestaciones recíprocas de un contrato oneroso debe exigir un razonable equilibrio, que es por lo demás la exigencia histórica de toda relación sinalagmática, pero a la vez impone un criterio de proporcionalidad, que viene exigido por una buena comprensión de la justicia contractual, de hondo arraigo en el Derecho natural. Emerge aquí con fuerza la causa como elemento autónomo, distinto del consentimiento o voluntad, porque por mucho que las partes hubieren adherido libremente al contrato, no puede admitirse un desequilibrio como el que descubre en el contrato que conoció el árbitro, don José Joaquín Ugarte.

Si se combinan ambos elementos, tanto el extrínseco, que es introducido al contrato por la voluntad que impulsa el acto y que luego lo persigue como fin, con este otro intrínseco, que exige que la retribución que obtienen las partes sea proporcional o razonable respecto del esfuerzo que hacen por obtenerla, se logra una perfecta comprensión de la doctrina de la causa y de la justicia contractual, que magníficamente la ha expuesto el señor Ugarte, capturándola en un caso, lamentablemente, de mayor ocurrencia del que querríamos. Se trata de una doctrina práctica y que le ha permitido al juez de esta causa anular un contrato recurriendo precisamente a un elemento que no siempre los jueces están dispuestos a darle sentido operativo.

En un motivo adicional, don José Joaquín Ugarte expone de qué manera el presupuesto de nulidad absoluta aparece de manifiesto en el acto o contrato, de manera de respetar la exigencia que en estos casos le impone al juez el artículo 1683 del Código Civil, que le autoriza para actuar formalmente ultra petita, es más, que le impone el deber de hacerlo. Expone el señor Ugarte Godoy que la indeterminación del precio de los hoteles, elemento que le ha permitido detectar la falta de causa, se manifiesta por la remisión a los reglamentos de cada hotel que en el contrato se hace y con ello se genera una absoluta incertidumbre respecto del precio que el cliente deberá pagar, no obstante estar predeterminado con precisión el valor que él ha debido pagar para optar a estos supuestos beneficios. Nos parece muy importante esta consideración, que confirma la doctrina ya asentada, de que es manifiesto el vicio cuando puede venirse a él sin otro elemento que no sea la lectura del contrato. En efecto, si los reglamentos de cada hotel en que se pida alojamiento no son parte del contrato, y en ellos queda entregada la facultad de fijar el valor por el servicio, quiere decir que el costo del alojamiento no queda determinado en el contrato, sino entregado a quien se le encarga la prestación del servicio.

Otra reflexión nos merece este último considerando. Si como se ha dicho, es la ley la que ordena al juez declarar la nulidad absoluta de un contrato, incluso pasando por sobre lo que el actor ha demandado, es porque se entiende que las reglas de nulidad absoluta son de orden público. El juez tiene el deber de hacer respetar tales normas, aunque el propio demandante no lo reclame, sea porque no le interese hacerlo o porque no lo haya adverti- 
do. A procesalistas con celo por el debido proceso puede parecerles un exceso que un juez pueda actuar en estos casos al margen del petitum de cada parte.

Cierro estos breves comentarios advirtiendo que una comprensión profunda de la doctrina de la causa, que es la que en este fallo expone el árbitro don José Joaquín Ugarte, demuestra que ella puede ser práctica y llegar a situaciones de ocurrencia diaria, o más sofisticadas, como es programar vacaciones en un horizonte de 25 años. Al mismo tiempo, se aprecia que el Derecho Civil puede responder a este tipo de situaciones, recurriendo a instituciones clásicas y no solo puede echarse mano a las reglas sobre protección de los derechos de los consumidores. 